\title{
ASSESSING THE IMPACT OF INTEGRATING INDIGENOUS KNOWLEDGES AND PERSPECTIVES IN ENGINEERING CURRICULA ON STUDENTS' LEARNING: THE DEVELOPMENT OF A Classroom CaSe STUdY
}

\author{
Afua Adobea Mante, Jillian Seniuk Cicek, Marcia Friesen, Leonnie Kavanagh \\ Centre for Engineering Professional Practice \& Engineering Education, Faculty of Engineering, University of Manitoba \\ Afua.Mante@umanitoba.ca
}

\begin{abstract}
Indigenous Peoples in Canada have practiced sustainability for centuries. Their knowledges, perspectives and design principles are applicable on both a local and global scale especially in our quest to find sustainable approaches to food security, energy independence, and climate change impacts. However, the opportunities for Indigenous Peoples to fully participate and formally offer knowledge and guidance on sustainable development in engineering education have been limited. Engineering training in Canada requires students to develop competency in the area of assessing the impact of engineering on society and the environment. Within this competency is the ability to understand and apply the concepts of sustainability to engineering activities. Engaging with Indigenous Peoples to understand their perspectives on engineering and society provides a platform to critically assess existing engineering curricula, expand the concept of sustainability, and come closer to a common place of understanding. Understanding the impact of incorporating Indigenous perspectives in the curricula on students' learning and understandings will help inform the further incorporation of Indigenous perspectives in engineering education. This paper presents the research methodology and instruments for a case study designed to explore students' learning in one engineering course that integrates an Indigenous Elder's perspectives on how to effectively communicate, engage, and obtain local knowledge on engineering projects with Indigenous communities in Manitoba. Findings will be used to inform engineering curriculum design that are enhanced by Indigenous knowledges and perspectives.
\end{abstract}

Keywords: Indigenous perspectives; engineering education; sustainability; classroom case study.

\section{INTRODUCTION}

From the year 1871 to 1921,11 treaties were made between the Crown and the Indigenous Peoples (First Nations,
Métis and Inuit Peoples) in Canada [1]. The treaties were negotiated to permit the sharing of lands and resources. They form the constitutional and moral basis of an alliance between Indigenous Peoples and Canada [2]. Irrespective of, or due to these treaties, rampant colonialism and racism has led to a dark history and troubled present between the Indigenous Peoples and non-Indigenous Canadians [3]. However, through the recent Truth and Reconciliation Commission's (TRC) 94 "Calls to Action," which includes reconciliation through education [4], a platform is created to revisit the past to acknowledge the colonial relationship between Indigenous Peoples and non-Indigenous Canadians, including the Government of Canada, understand the ways of life of Indigenous Peoples, and enhance the current curriculum with the knowledges, design principles and perspectives of Indigenous Peoples.

In response to the TRC's "Calls to Action," the University of Manitoba applied for, and was awarded, an NSERC Chair in Design Engineering for Sustainable Development and Enhanced Design Integration focused on initiatives to enhance the undergraduate engineering education through the inclusion of Indigenous knowledges and perspectives in engineering curricula. This is relevant as Manitoba has the highest Indigenous population (about $17 \%$ ) in Canada [5] and approximately $70 \%$ of University of Manitoba engineering graduates begin their professional careers in Manitoba, where a significant amount of engineering work takes place with Indigenous communities [6]. In the Design Chair's Action plan, the principles of accessibility and social inclusion inherent in sustainability are directed to emphasizing Indigenous knowledges, content, design principles and perspectives in the engineering curricula [3]. This initiative also aligns with the University of Manitoba Strategic Plan 2015-2020, which seeks to "incorporate Indigenous perspectives and knowledge[s] within its program offerings, and honour First Nations, Métis and Inuit traditions and cultures in its spaces" [7]. 
One of the strategies of the Design Chair is to restructure three engineering core courses to advance design for sustainability, that is, first-year Design in Engineering, third year Engineering Economics, and third year Technology, Society and the Future [3]. In particular, the work at the University of Manitoba to enhance engineering courses with Indigenous knowledges and perspectives is aimed to include "the history of Indigenous and non-Indigenous relationships, the history and structure of treaties, how treaties interact with development, the concept of social license, and the duty to consult and also examine how Indigenous communities operate, and different models of decision making" [3]. This paper describes the methodology and research instruments for a classroom case study designed to investigate the impact of incorporating Indigenous perspectives in the Technology, Society and the Future course.

\section{RESEARCH CONTEXT}

The Technology, Society and the Future course runs in both the Fall and Winter terms in the Faculty of Engineering, University of Manitoba, and is a required course for all undergraduate students. The course creates a learning environment in which students are introduced to, have discussions on, and analyze the impact of engineering on society and the environment and vice-versa. Students are also introduced to how morality, ethics and professionalism are part of the criteria for decision-making during infrastructure development. These three values and behaviors buttress the inseparable technical and societal context of engineering, which is core to the success of the profession [8] [9], and the engineering code of ethics primary canon that "practitioners shall hold paramount the safety, health and welfare of the public and the protection of the environment" [10].

As part of educating students on the societal context of engineering, instructors of the Technology, Society and the Future course have been inviting Indigenous speakers into the course since year 2014 to share their perspectives on the impact of engineering on the society through their lenses. This study focuses on the Winter 2018 term of the Technology, Society and the Future course, in which an Indigenous Elder was invited to share his perspectives on communicating and engaging with Indigenous communities and discussing the impact of engineering projects on their local society. The instructor for this section was motivated by her philosophy of practicing "good engineering." She believed that by introducing students to Indigenous perspectives on engineering and society, students would be afforded a pathway by which to become aware of, understanding of, and sensitive to Indigenous perspectives in engineering in order to successfully deliver projects that mitigate impacts and realize benefits for Indigenous communities. Specifically, when students were involved in infrastructure development, they could use cultural awareness, understanding, and sensitivity to guide their work as professional engineers.

In March 2018, An Elder-in-Residence at the University of Manitoba, was invited to share his perspectives with students in the Technology, Society and the Future course on what to consider during consultations with Indigenous communities during infrastructure development. The Elder's talk lasted one hour. $\mathrm{He}$ introduced students to the "Medicine Wheel," which represents the continuous interaction and interconnectedness of the spirit, emotion, physical and mental qualities of life [11]. Students were taught the significance of these aspects to the wellbeing of a person and how these aspects form the frame through which to develop holistic solutions to societal challenges. At the end of the Elder's talk, students were asked to reflect on his perspectives and write a-page-long paper explaining their understanding of, and critical thinking about the perspectives shared, and their lessons learned. Lessons learned included how the Elder's perspectives applied to the students' own personal contexts, and how they could be adapted to students' professional engineering practice.

The objective of this case study is to provide an opportunity to assess how students' learning has been impacted by the integration of Indigenous perspectives into an engineering course. Understanding the effect on students' learning will inform engineering educators on how to design engineering curricula to add or extend Indigenous content. This case study provides one opportunity to examine how to effectively move forward to achieve these goals. It is guided by the research question, How do Indigenous perspectives in an engineering course impact students' understanding of the impact of engineering on society and the environment?

\section{RESEARCH DESIGN}

\subsection{Research Methodology}

This research uses a case study methodology to investigate how Indigenous perspectives impact students' understanding of the impact of engineering on society and the environment. An intrinsic case study, which is a qualitative approach, will be conducted, bounded by place, time, and specific individuals [12] [13]. This is a unique case as it explores one group of students' understanding of the impact of engineering on Indigenous communities from an Indigenous Elder's perspective from multiple data sources in one section of the Technology, Society and Future course taught at the Faculty of Engineering at the University of Manitoba in Winter 2018. 


\subsection{Data collection instruments}

Qualitative data forms will be collected including students' reflective writing texts, one student focus group, the course syllabus, course assessment tools, an interview with the instructor, and a conversation with the Elder to assess the impact of Indigenous perspectives in an engineering course on students' learning.

The reflective texts, course syllabus, and course assessment tools will be analyzed before the focus group discussion takes place. The analysis of these data will be used to develop the focus group discussion guide. This will enable the researchers to explore the findings from these data more deeply in the student focus group. Following the focus group discussion, the instructor interview will be conducted and the conversation with the Elder will take place. This will enable the researchers to discuss the impact of the Elder's perspectives on students' learning with the instructor and the Elder in the context of the instructor and Elder's intended learning outcomes. It will offer the researchers the opportunity to gain additional perspective from the instructor and the Elder with respect to their expectations and the research findings.

\subsection{Data analysis}

Data will be coded, categorized, and grouped using the constant comparative method to develop a "substantivelevel theory" [11] [12]. The information obtained from the data will be used to inform the further development of engineering curricula to support design for sustainability as proposed by the NSERC Chair in Design Engineering at the University of Manitoba.

\subsection{Ethics}

The access to student writing texts and information gathering from the focus group discussion, interview with the instructor and conversation with the Elder require ethics approval. The ethics protocol has been developed and sent for approval by the Ethics Board that governs educational research activity involving human participants at the University of Manitoba.

\section{EXPECTED OUTCOMES AND SIGNIFICANCE OF THE STUDY}

Integrating Indigenous perspectives into an engineering course is one step towards teaching design for sustainability and the inherent principle of accessibility and social inclusion. Understanding the impact of incorporating Indigenous perspectives into the curricula on students' learning will inform the improvement and development of successful engineering projects. By incorporating Indigenous perspectives into engineering curricula, we will empower engineering students to be more culturally and socially sensitive and aware, and advance students' understanding of sustainable design and development as "good engineering," which will address a relevant need for the engineering industry in Canada, and around the world.

The findings from this study will encourage and inform other engineering faculty about integrating Indigenous perspectives into engineering curricula. The approach used in this paper to incorporate Indigenous perspectives in an engineering classroom, and of the research design to analyze the impact on students' learning, are intended to provide a platform to stimulate discussion with other engineering educators who are engaged in, or interested in starting this work. Preliminary results will be available by the time of the conference and will be included in the podium presentation of the paper.

\section{ACKNOWLEDGEMENT}

This work is supported by the NSERC Chair in Design Engineering at the University of Manitoba.

\section{REFERENCES}

[1] Michelle Filice, "Numbered Treaties," The Canadian Encyclopedia, Available at: www.thecanadianencyclopedia.ca/en/article/numbered-treaties, 2016.

[2] Anthon J. Hall, "Treaties with Indigenous Peoples in Canada," The Canadian Encyclopedia, Available at www.thecanadianencyclopedia.ca/en/article/aboriginal-treaties, 2018 .

[3] Marcia R. Friesen and Randy Herrmann, "Indigenous knowledge, perspectives, and design principles in the engineering curriculum," in Proceedings Canadian Engineering Education Association (CEEA-ACEG18) conference, University of British Columbia, June $3-6,2018$.

[4] Truth and Reconciliation Commission of Canada, Truth and Reconciliation Commission of Canada Calls to Action, 2015.

[5] Statistics Canada, Aboriginal peoples: Fact Sheet for Manitoba, Available: https://www150.statcan.gc.ca/n1/pub/89656-x/89-656-x2016008-eng.htm (Assessed March 1), 2019.

[6] Beddoes, J. and Friesen, M., "NSERC Chair in Design Engineering for Sustainable Development and Enhanced Design Integration," University of Manitoba, Winnipeg, Manitoba, Canada, 2018

[7] University of Manitoba, "Taking Our Place: University of Manitoba Strategic Plan, 2015-2020," University of Manitoba, Winnipeg, Manitoba, Canada, 2019. Available: http://umanitoba.ca/admin/president/strategic_plan/index.html

[8] Dukhana, N., Schumacka, M. R. and Daniels, J. J, "Service learning as pedagogy for promoting social awareness of mechanical engineering students," International Journal of Mechanical Engineering Education, vol 37(1), pp: 78-86, 2012. 
[9] Engineers Canada, "Canadian Engineering Accreditation Board, Accreditation Criteria and Procedures," Engineers Canada, 2017.

[10] Engineers Geoscientists Manitoba (EGM), Code of Ethics, Engineers Geoscientists Manitoba, Winnipeg, Manitoba, Canada, Available: http://www.apegm.mb.ca/ActBylawsCode.html, 2019.

[11] Fontaine, Leah, "Mashkiki Beshibii'igan: Medicine Line," Workshop sponsored by the Centre for the Advancement of Teaching and Learning, University of Manitoba, Canada, 2018.

[12] van Note Chism, N., Douglas, E. and Hilson, W. J. Jr., "Qualitative research basics: A guide for engineering educators, Rigorous Research in Engineering Education: Creating a Community of Practice," National Science Foundation, U.S.A., Report Number DUE-0341127, 2008.

[13] Creswell, J. W., "Qualitative inquiry and research design: Choosing among five approaches," 3rd ed. L.A., CA: Sage, 2013. 